\title{
Erratum zu: Workshop „Empirisch Forschen in der Medizinethik“"
}

\author{
Halle (Saale), 27.-28. November 2019
}

\section{Andre Nowak $\cdot$ Philipp Karschuck}

Online publiziert: 19. Juli 2021

(C) Der/die Autor(en) 2021

\section{Erratum zu:}

\section{Ethik Med 2020}

https://doi.org/10.1007/s00481-020-00581-3

Der Artikel „Workshop „Empirisch Forschen in der Medizinethik“. Halle (Saale), 27.-28. November 2019“ von Andre Nowak und Philipp Karschuck wurde ursprünglich Online First ohne „Open Access“ auf der Internetplattform des Verlags publiziert. Nach der Veröffentlichung in Bd. 32 Heft 3 pp. 293-295 hatten sich die Autoren für eine „Open Access“-Veröffentlichung entschieden. Das Urheberrecht des Artikels wurde deshalb in (C) Der/die Autoren 2020 geändert. Dieser Artikel ist jetzt unter der Creative Commons Namensnennung 4.0 International Lizenz veröffentlicht, welche die Nutzung, Vervielfältigung, Bearbeitung, Verbreitung und Wiedergabe in jeglichem Medium und Format erlaubt, sofern Sie den/die ursprünglichen Autor(en) und die Quelle ordnungsgemäß nennen, einen Link zur Creative Commons Lizenz beifügen und angeben, ob Änderungen vorgenommen wurden. Die in diesem Artikel enthaltenen Bilder und sonstiges Drittmaterial unterliegen ebenfalls der genannten Creative Commons Lizenz, sofern sich aus der Abbildungslegende nichts anderes ergibt. Sofern das betreffende Material nicht unter der genannten Cre-

Die Online-Version des Originalartikels ist unter https://doi.org/10.1007/s00481-020-00581-3 zu finden.

\footnotetext{
Andre Nowak $(\bowtie)$

Institut für Geschichte und Ethik der Medizin, Profilzentrum Gesundheitswissenschaften, Medizinische Fakultät, Martin-Luther-Universität Halle-Wittenberg, Magdeburger Straße 8, 06112 Halle (Saale), Deutschland

E-Mail: andre.nowak@uk-halle.de

Philipp Karschuck

Klinik und Poliklinik für Urologie, Universitätsklinikum Carl Gustav Carus, Technische Universität Dresden, Dresden, Deutschland
} 
ative Commons Lizenz steht und die betreffende Handlung nicht nach gesetzlichen Vorschriften erlaubt ist, ist für die oben aufgeführten Weiterverwendungen des Materials die Einwilligung des jeweiligen Rechteinhabers einzuholen. Weitere Details zur Lizenz entnehmen Sie bitte der Lizenzinformation auf http://creativecommons. org/licenses/by/4.0/deed.de.

Funding Open Access funding enabled and organized by Projekt DEAL.

Open Access Dieser Artikel wird unter der Creative Commons Namensnennung 4.0 International Lizenz veröffentlicht, welche die Nutzung, Vervielfältigung, Bearbeitung, Verbreitung und Wiedergabe in jeglichem Medium und Format erlaubt, sofern Sie den/die ursprünglichen Autor(en) und die Quelle ordnungsgemäß nennen, einen Link zur Creative Commons Lizenz beifügen und angeben, ob Änderungen vorgenommen wurden.

Die in diesem Artikel enthaltenen Bilder und sonstiges Drittmaterial unterliegen ebenfalls der genannten Creative Commons Lizenz, sofern sich aus der Abbildungslegende nichts anderes ergibt. Sofern das betreffende Material nicht unter der genannten Creative Commons Lizenz steht und die betreffende Handlung nicht nach gesetzlichen Vorschriften erlaubt ist, ist für die oben aufgeführten Weiterverwendungen des Materials die Einwilligung des jeweiligen Rechteinhabers einzuholen.

Weitere Details zur Lizenz entnehmen Sie bitte der Lizenzinformation auf http://creativecommons.org/ licenses/by/4.0/deed.de. 